\title{
Usefulness of central venous saturation as a predictor of thiamine deficiency in critically ill patients: a case report
}

Genri Numata* (D), Satoshi Kodera, Hiroyuki Kiriyama, Atsuko Nakayama, Eisuke Amiya, Arihiro Kiyosue, Masaru Hatano, Eiki Takimoto, Masafumi Watanabe and Issei Komuro

\begin{abstract}
Background: Central venous oxygen saturation $\left(\mathrm{SCvO}_{2}\right)$ reflects the balance of oxygen delivery and consumption. Low $\mathrm{ScvO}_{2}$ indicates the presence of inadequate oxygen delivery, while high $\mathrm{ScvO}_{2}$ indicates reduced oxygen consumption and is sometimes associated with a high mortality rate in critically ill patients from dysoxia. Thiamine is an essential cofactor in cellular aerobic metabolism. Thiamine deficiency is more prevalent than was previously thought, and underlies severe conditions in critically ill patients. However, currently, there is no rapid diagnostic test for thiamine deficiency. Considering oxygen flux, high $\mathrm{ScvO}_{2}$ might be associated with thiamine deficiency.

Case presentation: A 70-year-old man admitted to the hospital with chief complaint of malaise and edema. He was diagnosed with heart failure with preserved ejection function and was treated with loop diuretics, which resulted in shock. Venoarterial extracorporeal membrane oxygenation and intra-aortic balloon pumping was indicated. The right heart catheter showed high $\mathrm{ScvO}_{2}$, normal cardiac output, and low systemic vascular resistance. Thiamine deficiency was suspected and we started the thiamine infusion. His hemodynamic status improved after thiamine replacement. After his recovery, it was discovered that he had a 1-month history of anorexia and thiamine deficiency. His final diagnosis was beriberi.

Conclusions: The current case showed the relation between thiamine deficiency and high $\mathrm{ScvO}_{2}$. A literature review also suggested that thiamine deficiency is associated with high $\mathrm{ScvO}_{2}$. Thiamine deficiency causes impaired tissue oxygen extraction, which could lead to high $\mathrm{ScvO}_{2}$. In this context, high $\mathrm{ScvO}_{2}$ might serve as a predictor of thiamine deficiency in critically ill patients.
\end{abstract}

Keywords: Thiamine, Oxygen consumption, Beriberi, Shock, Diuretics, Central venous catheter

\section{Background}

Central venous oxygen saturation $\left(\mathrm{ScvO}_{2}\right)$ provides an estimate of oxygen flux, reflecting balance of oxygen delivery and consumption. Low $\mathrm{ScvO}_{2}$ indicates the presence of inadequate oxygen delivery and $\mathrm{ScvO}_{2}<70 \%$ has been accepted as a maker for hypo-perfusion in the management of shock patients or postoperative patients. On the other hand, high $\mathrm{ScvO}_{2}$ indicates reduced oxygen consumption in systemic organs typically from dysoxia with mitochondrial dysfunction and has been associated with a high mortality rate in critically ill patients [1-3].

\footnotetext{
* Correspondence: gen-numata@kib.biglobe.ne.jp

Department of Cardiovascular Medicine, Graduate school of Medicine, The University of Tokyo, 7-3-1 Hongo, Bunkyo-ku, Tokyo 1130033, Japan
}

Thiamine, a cofactor for pyruvate dehydrogenase $(\mathrm{PDH})$, plays an essential role in cellular aerobic metabolism. Growing evidence suggests that thiamine deficiency is more prevalent than was previously thought, and underlies severe conditions in critically ill patients [3]. However, currently, there is no rapid diagnostic test for thiamine deficiency and thiamine activity, which is useful for diagnosis, is not easily detected in some countries. In the presence of thiamine deficiency, PDH fails to convert pyruvate into acetyl-CoA that enters Krebs cycle to produce adenosine triphosphate (ATP) using oxygen, and thus oxygen consumption is reduced in various tissues. Therefore, high $\mathrm{ScvO}_{2}$ values might be a good and convenient marker for thiamine deficiency in 
critically ill patients. Here, we report a case of heart failure, who was successfully diagnosed with thiamine deficiency using high $\mathrm{ScvO}_{2}$ values after presenting shock from diuretics treatment.

\section{Case presentation}

A 70-year-old man presented to our hospital with exaggerated general malaise and leg edema. His blood pressure on admission was $90 / 50 \mathrm{mmHg}$, heart rate was 84 beats/ min, body temperature $36.5^{\circ} \mathrm{C}$, and respiratory rate 20/ min with $99 \%$ oxygen saturation on ambient air. He had pitting edema of the lower legs and he gained about $10 \mathrm{~kg}$ weight. Blood tests showed mild renal and hepatic impairment (blood urea nitrogen; $39 \mathrm{mg} / \mathrm{dL}$; creatinine, $1.3 \mathrm{mg} /$ $\mathrm{dL}$; aspartate aminotransferase, $52 \mathrm{U} / \mathrm{L}$; alanine transaminase, $53 \mathrm{U} / \mathrm{L}$; gamma-glutamyl transferase, $177 \mathrm{U} / \mathrm{L}$; alkaline phosphatase, $296 \mathrm{U} / \mathrm{L}$ ), and the brain natriuretic peptide level was $317 \mathrm{pg} / \mathrm{mL}$. There was no evidence of neurological abnormality. A plain radiograph of his chest revealed heart dilation and pleural edema. Transthoracic echocardiography (TTE) showed mild pericardial effusion, an ejection fraction of $56 \%$, mild tricuspid valve regurgitation (right ventricular systolic pressure, $44 \mathrm{mmHg}$ ), and the diameter of inferior vena cava of $22 \mathrm{~mm}$ with no respiratory variations. He drank 40 to $80 \mathrm{~g}$ of alcohol a day. Because he was diagnosed with heart failure with preserved ejection fraction and volume overload, he was treated with infusion of loop diuretics (furosemide $20 \mathrm{mg}$ / day). However diuretics did not work well (urine output, $500 \mathrm{ml} /$ day) and 1 day after starting the diuretic infusion his malaise worsened. His systolic blood pressure suddenly decreased to $50 \mathrm{mmHg}$. Electrocardiography showed rapid atrial fibrillation (Heart rate, 150 beats/min), low voltage at limb leads, no ST-T change and no prolonged QT interval. TTE showed a little increased pericardial effusion with normal ejection fraction. Cardiac tamponade and atrial fibrillation might lead to his shock status therefore we performed electrical cardioversion and pericardiocentesis, resulting in no response. Fluid resuscitation $(1 \mathrm{~L})$ and norepinephrine $(1 \mu \mathrm{g} / \mathrm{kg} / \mathrm{min})$ also did not improve his hemodynamic status. Thus we began venoarterial extracorporeal membrane oxygenation (ECMO) and intra-aortic balloon pumping (IABP). Before ECMO and IABP induction, the right heart catheter showed his $\mathrm{ScvO}_{2}$ to be $92 \%$, cardiac index $2.2 \mathrm{~L} / \mathrm{min} / \mathrm{m}^{2}$, pulmonary artery wedge pressure $28 \mathrm{mmHg}$, mean pulmonary artery pressure $36 \mathrm{mmHg}$, and systemic vascular resistance 596 dyne.s $/ \mathrm{cm}^{5}$ on dobutamine $10 \mu \mathrm{g} / \mathrm{kg} / \mathrm{min}$ and norepinephrine $1 \mu \mathrm{g} / \mathrm{kg} / \mathrm{min}$. Coronary angiography showed no stenosis and endomyocardial biopsy revealed no significant sings of myocarditis or cardiomyopathy.

As low systemic vascular resistance and high $\mathrm{ScvO}_{2}$ might be caused by thiamine deficiency, we submitted blood sample for thiamine level and started an intravenous infusion of $100 \mathrm{mg}$ thiamine. There was no evidence of infection or adrenal insufficiency. At $24 \mathrm{~h}$ after the thiamine administration, his $\mathrm{ScvO}_{2}$ decreased from 92 to $82 \%$, and his lactate level decreased, from 90.9 to $9.0 \mathrm{mg} / \mathrm{dL}$ (Fig. 1). His blood pressure recovered to the normal range. We thus stopped the catecholamine administration and ECMO. Five days after his recovery from shock, we discovered that his thiamine level at the point of ECMO induction was $14 \mathrm{ng} / \mathrm{mL}$ (normal range $24-66 \mathrm{ng} / \mathrm{mL}$ ). Also, we obtained the additional information on a 1-month history of anorexia. After 2-week thiamine replacement, his malaise and edema disappeared with no other treatments diuretics. His $\mathrm{ScvO}_{2}$ before discharge was $60 \%$. Together all, a diagnosis of cardiac beriberi was confirmed.

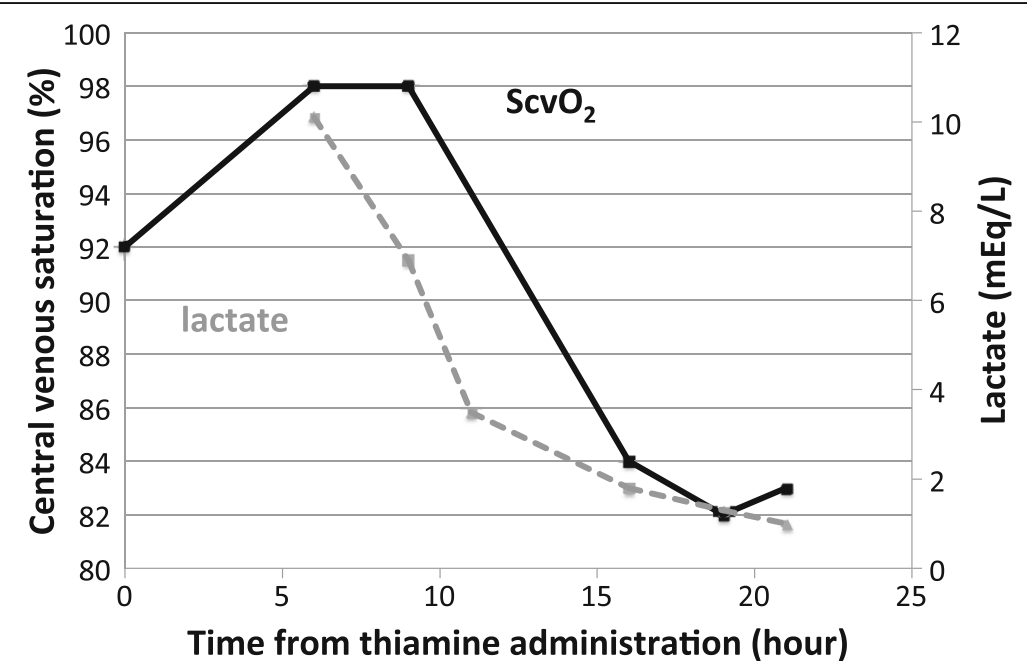

Fig. 1 Central venous saturation and serum lactate levels after thiamine administration. Note that both parameters recovered soon after the thiamine replacement therapy 
Table 1 Previously reported cases of high central venous saturation associated with thiamine deficiency and shock

\begin{tabular}{llllll}
\hline Author (ref) & Year & Patient character & $\mathrm{ScvO}_{2}(\%)$ & Lactate $(\mathrm{mg} / \mathrm{dL})$ & Thiamine concentration $(\mathrm{ng} / \mathrm{mL})$ \\
\hline Misumida et al. [9] & 2014 & 61-year-old man & 78 & 75 & 11 \\
Majima et al. [4] & 2013 & 1-year-and-4-mo-old boy & 82 & 114 & 12 \\
Kountchev et al. [10] & 2005 & 50-year-old man & 78 & 186.5 & Not examined \\
Diltoer et al. [11] & 2004 & 62-year-old woman & 69 & 122.5 & Below the detection limit \\
Ito et al. [12] & 2002 & 73-year-old man & 87 & 196.8 & 16 \\
\hline
\end{tabular}

\section{Discussion}

The current case revealed two important points. High $\mathrm{ScvO}_{2}$ might be associated with thiamine deficiency, and a patient's hemodynamic status in the presence of thiamine deficiency could become worse with the administration of loop diuretics.

Thiamine (i.e., vitamin B1) is a water-soluble vitamin, and thiamine pyrophosphate, the active form of thiamine, serves as a catalyst of $\mathrm{PDH}$ in the reactions of pyruvate to acetyl coenzyme $\mathrm{A}$ and $\alpha$-ketoglutarate to succinyl coenzyme A in the Krebs cycle, contributing to the synthesis of ATP. Thus, thiamine deficiency could cause impaired tissue oxygen extraction leading to lactic acidosis with high $\mathrm{ScvO}_{2}$. Lactate is actually very helpful for management of shock patients and our data actually showed the parallel transition in $\mathrm{ScvO}_{2}$ and lactate. However, lactate alone might be insufficient to evaluate the tissue oxygen flux. Elevated level of lactate is the result of impaired tissue oxygenation and it does not reveal the cause. On the other hand, $\mathrm{ScvO}_{2}$ gives us the information about the tissue oxygen consumption and not insufficient oxygen delivery.

In the literature, we found only one report suggesting a relation between cardiac beriberi and high $\mathrm{ScvO}_{2}$ (in a case of pediatric heart failure) [4] and no papers exploring the possibility of a relation between high $\mathrm{ScvO}_{2}$ and thiamine deficiency in critically ill adults.

In this case, the loop diuretics might have exacerbated the patient's thiamine deficiency by increasing urinary excretion of thiamine. Although recent studies revealed that the chronic use of loop diuretics might not be associated with thiamine deficiency because of diuretic resistance $[5,6]$, a short-term use of loop diuretics in combination with other diuretics could induce thiamine deficiency via inhibiting its reabsorption [7].

Some patients with multi-organ failure, such as septic shock, show high $\mathrm{ScvO}_{2}$, and it has been implicated as a poor prognostic factor [1]. Although it is conceivable that mitochondrial dysfunction underlies high $\mathrm{ScvO}_{2}$ values and has received considerable attention, no consensus has been reached as to its precise pathological mechanism [8]. Thiamine deficiency might play some role in mitochondrial dysfunction in shock patients with high $\mathrm{ScvO}_{2}$.

We conducted a literature review using PubMed and Google Scholar. English language case reports published between 1990 and 2017 were reviewed using the search terms" beriberi,"” shock," and" thiamine." The review identified five articles describing $\mathrm{ScvO}_{2}$ [4, 9-12]. Each case described high $\mathrm{ScvO}_{2}$ (Table 1). This finding may support our hypothesis concerning the association of high $\mathrm{ScvO}_{2}$ and thiamine deficiency.

In a recent randomized trial, patients with septic shock and thiamine deficiency exhibited a significant improvement in the mortality rate after applying intravenous thiamine infusion [13]. Although patients with thiamine deficiency would be better served by thiamine replacement therapy, the diagnosis of thiamine deficiency depends mainly on clinical suspicion and therefore might be difficult, especially on admission. In addition most cardiac beriberi leads to high-output heart failure, while some patients exhibit low cardiac output (shoshin beriberi) [14]. Besides, it is well known that the serum thiamine level does not necessarily reflect thiamine deficiency of the whole body [8]. In this context, thiamine deficiency might be underestimated. Not to mention clinical history or physical findings were important; however, measuring $\mathrm{ScvO}_{2}$ would help identify patients with thiamine deficiency especially in shock status. Thus, administration of thiamine could improve the mortality rate among critically ill patients.

\section{Conclusion}

High $\mathrm{ScvO}_{2}$ might serve as a predictor of thiamine deficiency in critically ill patients, with loop diuretics possibly leading to further depletion of thiamine.

\section{Abbreviations \\ ATP: Adenosine triphosphate; ECMO: Extracorporeal membrane oxygenation; IABP: Intra-aortic balloon pumping; PDH: Pyruvate dehydrogenase; \\ $\mathrm{SCVO}_{2}$ : Central venous oxygen saturation; TTE: Transthoracic \\ echocardiography}

\section{Acknowledgements}

We thank Nancy Schatken, BS, MT (ASCP), from Edanz Group

(www.edanzediting.com/ac) for editing a draft of this manuscript.

\section{Funding}

Not applicable.

Availability of data and materials

The datasets used and/or analyzed during the current study are available from the corresponding author on reasonable request. 


\section{Authors' contributions}

All authors contributed equally to the manuscript. All authors read and approved the final manuscript.

\section{Ethics approval and consent to participate}

Not applicable.

\section{Consent for publication}

This was obtained from the patient.

\section{Competing interests}

The authors declare that they have no competing interests.

\section{Publisher's Note}

Springer Nature remains neutral with regard to jurisdictional claims in published maps and institutional affiliations.

Received: 4 September 2017 Accepted: 31 October 2017

Published online: 06 November 2017

\section{References}

1. Textoris J, Fouché L, Wiramus S, et al. High central venous oxygen saturation in the latter stages of septic shock is associated with increased mortality. Crit Care. 2011;15:R176.

2. Balzer F, Sander M, Simon M, et al. High central venous saturation after cardiac surgery is associated with increased organ failure and long-term mortality: an observational cross-sectional study. Crit Care. 2015;19:168

3. Singer $M$. The role of mitochondrial dysfunction in sepsis-induced multiorgan failure. Virulence. 2014;5:66-72.

4. Majima N, Umegaki O, Soen M. Use of central venous saturation monitoring in a patient with pediatric cardiac beriberi. World J Clin Cases. 2013:1:205-7.

5. Sole MJ, Barr A, Keith ME. The prevalence of thiamin deficiency in hospitalized patients with congestive heart failure. J Am Coll Cardiol. 2006;47:354-61

6. Sica DA. Loop diuretic therapy, thiamine balance, and heart failure. Pharmacology in Congestive Heart Failure. 2007;13:244-7.

7. Larkin JR, Zhang F, Godfrey L, et al. Glucose-induced down regulation of thiamine transporters in the kidney proximal tubular epithelium produces thiamine insufficiency in diabetes. PLoS One. 2012;7:e53175.

8. Mallat J, Lemyze M, Thevenin D. Do not forget to give thiamine to your septic shock patient! J Thorac Dis. 2016;8:1062-6.

9. Misumida N, Umeda H, Iwase M. Shoshin beriberi induced by long-term administration of diuretics: a case report. Case Reports Cardiol. 2014;2014:1-5.

10. Kountchev J, Bijuklic K, Bellmann R, et al. A patient with severe lactic acidosis and rapidly evolving multiple organ failure: a case of shoshin beriberi. Intensive Care Med. 2005;31:1004.

11. Diltoer MW, Troubleyn J, Lauwers R, et al. Ketosis and cardiac failure: common signs of a single condition. Eur J Emerg Med. 2004;11:172-5.

12. Ito $M$, Tanabe $Y$, Suzuki K. Shoshin beriberi with vasospastic angina pectoris. Circ J. 2002:66:1070-2.

13. Donnino MW, Andersen LW, Chase M, et al. Randomized, double-blind, placebo-controlled trial of thiamine as a metabolic resuscitator in septic shock. Crit Care Med. 2016:44:360-7.

14. Mclntyre N, Stanley NN. Cardiac beriberi: two modes of presentation. Br Med J. 1971:3:567-9.

\section{Submit your next manuscript to BioMed Central} and we will help you at every step:

- We accept pre-submission inquiries

- Our selector tool helps you to find the most relevant journal

- We provide round the clock customer support

- Convenient online submission

- Thorough peer review

- Inclusion in PubMed and all major indexing services

- Maximum visibility for your research

Submit your manuscript at www.biomedcentral.com/submit 